\title{
DO TAX CUTS PRODUCE MORE EINSTEINS? THE IMPACTS OF FINANCIAL INCENTIVES VS. EXPOSURE TO INNOVATION ON THE SUPPLY OF INVENTORS
}

\section{Alex Bell}

Harvard University

Xavier Jaravel

London School of Economics

\section{Raj Chetty}

Harvard University and NBER

Neviana Petkova

Office of Tax Analysis, US Treasury

\section{John Van Reenen}

MIT and Centre for Economic

Performance

Acknowledgments: This paper draws heavily on Bell et al. (2017) (the working paper version of Bell et al. (2019)) as well as Van Reenen's 2017 Schumpeter Lecture at the summer meetings of the European Economic Association in Lisbon. The opinions expressed in this paper are those of the authors alone and do not necessarily reflect the views of the Internal Revenue Service, U.S. Department of the Treasury. We would particularly like to thank Philippe Aghion for inspiration and many insightful comments. This research was funded by the National Science Foundation, the National Institute on Aging Grant T32AG000186, the European Research Council, the Economic and Social Research Council at CEP, the Washington Center for Equitable Growth, and the Kauffman Foundation.

E-mail: ambell@gmail.com (Bell); chetty@fas.harvard.edu (Chetty); xavier.jaravel@gmail.com (Jaravel); neviana.petkova@treasury.gov (Petkova); vanreene@mit.edu (Van Reenen) 


\section{Abstract}

Many countries provide financial incentives to spur innovation, ranging from tax incentives to research and development grants. In this paper, we study how such financial incentives affect individuals' decisions to pursue careers in innovation. We first present empirical evidence on inventors' career trajectories and income distributions using de-identified data on 1.2 million inventors from patent records linked to tax records in the U.S. We find that the private returns to innovation are extremely skewed - with the top $1 \%$ of inventors collecting more than $22 \%$ of total inventors' income - and are highly correlated with their social impact, as measured by citations. Inventors tend to have their most impactful innovations around age 40 and their incomes rise rapidly just before they have high-impact patents. We then build a stylized model of inventor career choice that matches these facts as well as recent evidence that childhood exposure to innovation plays a critical role in determining whether individuals become inventors. The model predicts that financial incentives, such as top income tax reductions, have limited potential to increase aggregate innovation because they only affect individuals who are exposed to innovation and have no impact on the decisions of star inventors, who matter most for aggregate innovation. Importantly, these results hold regardless of whether the private returns to innovation are known at the time of career choice. In contrast, increasing exposure to innovation (e.g., through mentorship programs) could have substantial impacts on innovation by drawing individuals who produce high-impact inventions into the innovation pipeline. Although we do not present direct evidence supporting these model-based predictions, our results call for a more careful assessment of the impacts of financial incentives and a greater focus on alternative policies to increase the supply of inventors. (JEL: L2, M2, O32, O33)

\section{Introduction}

The importance of innovation for economic growth (e.g., Romer 1990, Aghion and Howitt 1992) has led to considerable policy interest in increasing rates of innovation. 
The most common approach to spur innovation is to provide financial incentives to innovate, such as tax reductions or research and development (R\&D) grants. Although a large body of research has evaluated the impacts of such financial incentives on behavior in firms (e.g., Hall and Rosenberg 2010), there has been less work on how financial incentives affect whether individuals choose to become inventors - the "supply" of inventors in the terminology of Romer 2000).

In this paper, we study how financial incentives affect individuals' decisions to pursue careers in innovation, in two steps. We first document a set of facts about inventors' careers in the labor market that shed light on the structure of returns to innovation. We then construct a stylized model of career choice that matches these facts as well as other recent evidence to analyze how financial incentives affect the supply of inventors.

In the first part of the paper, we analyze inventors' careers using a longitudinal dataset covering 1.2 million inventors in the United States $\square^{1}$ This dataset was constructed by Bell et al. (2019) by linking the universe of patent applications and grants in the U.S. between 1996 and 2014 to federal income tax returns. These administrative data allow us to track inventors' incomes and patent rates from the beginning to the end of their careers in a comprehensive manner.

1. Following prior work, we define an "inventor" as an individual who holds a patent. Patents provide a useful proxy for innovation at scale, but have well-known limitations (e.g., Griliches 1990 and OECD 2009). 
We find that the financial returns to innovation are highly skewed and highly correlated with their scientific impact - two key facts which we show using our model imply that small changes in financial incentives will not affect aggregate innovation significantly. The highest-paid $1 \%$ of inventors (whose annual incomes exceed $\$ 1.6$ million per year) earn more than $22 \%$ of total inventors' income. The distribution of income among patent-holders is as skewed as the distribution of income in the population as a whole. Individuals with highly cited patents have much higher incomes, suggesting that the private benefits of innovation are correlated with their social returns 2

Next, we turn to the dynamics of inventors' careers. We find that inventors tend to make their highest-impact (most cited) discoveries when they are in their mid-forties, well after they make initial career choices, consistent with the findings of Jones et al. (2014). Interestingly, inventors' incomes tend to rise rapidly in the years just before patents are granted, consistent with Depalo and Di Addario (2014). This result implies that much of the individual return to innovation comes not from the patent itself the component of inventors' income that has received the most attention in prior work (e.g., ?, Kline et al. 2017) - but from associated business income and salaries.

2. We follow prior work (e.g., Jaffe et al. 1993) in using patent citations as a proxy for a patent's technological merit and social impact. Although citations are an imperfect proxy for impact, they are well correlated with other measures of value, such as firm's profits and market valuations

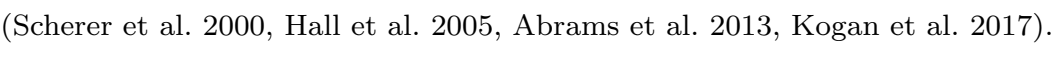


In the second part of the paper, we characterize the implications of our empirical findings for policies to increase innovation using a simple model of career choice. We build a model that matches both the facts on career trajectories described above and evidence from our companion paper (Bell et al. 2019) on the importance of childhood exposure to innovation. In that paper - which complements the present study by analyzing inventors' lives before entering the labor market - we showed that exposure to innovation during childhood has significant causal effects on children's propensities to invent. In particular, children whose families move to a high-innovation area at young ages are more likely to become inventors. These impacts are technology-class and gender specific. Children who grow up in a neighborhood or family with a high innovation rate in a specific technology class are more likely to patent in exactly the same class. Girls are more likely to invent in a particular class if they grow up in an area with more women (but not men) who invent in that class. Since these genderand technology class-specific impacts are unlikely to be driven by factors that affect general human capital accumulation (such as the quality of schools), we conclude that they must be driven by more narrow exposure effects - i.e., information or role model effects that motivate some children to pursue innovation.

Motivated by these findings, we construct a model in which three factors determine whether an individual pursues innovation: financial incentives, exposure to innovation, and preferences. We model exposure as a stochastic binary variable: individuals who do not receive exposure to innovation do not consider an inventor career, whereas those who receive exposure decide whether to pursue innovation by maximizing 
expected lifetime utility as in Roy (1951) and Hsieh et al. (2016). To match our empirical findings on the return to innovation, we model payoffs in the innovation sector using a Pareto distribution, focusing on the case where the skewness of the payoffs is large, either due to differences in ex-ante abilities to innovate or ex-post shocks. We also assume that inventors' salaries are proportional to social impact of their inventions given our result that citations and salaries are strongly correlated. Finally, we assume that exposure to innovation is uncorrelated with individuals' abilities to innovate - an assumption that is consistent with evidence on heterogeneity across subgroups from Bell et al. (2019).

Using this model, we compare the impacts of two types of policies on innovation: increasing private financial returns (e.g., by cutting top income tax rates) and increasing exposure (e.g., through mentorship programs). The model implies that the potential to increase innovation by reducing top taxes is limited, for three reasons. First, such policies only affect the subset of individuals who have been exposed to the possibility of an inventor career. Second, if the returns to innovation are forecastable at the point of career choice, such policies would only induce inventors of marginal quality to enter the field rather than star inventors. In our data, the mean annual income of those with patents in the top $1 \%$ of the citation distribution is more than $\$ 1$ million between ages $40-50$. The decisions of these star inventors are unlikely to be affected by small changes in financial incentives, making aggregate quality-weighted 
innovation relatively insensitive to tax rates (Jaimovich and Rebelo 2017) $\left.\right|^{3}$ Third, if the returns to innovation are uncertain at the point of career choice, the elasticity of innovation with respect to top income tax rates is likely to be small in a standard expected utility model because tax changes only affect payouts when inventors have very high incomes and low marginal utility.

In contrast, the model implies that increasing exposure can have substantial impacts on quality-weighted innovation by drawing individuals who would produce high-impact inventions ("Lost Einsteins" or "Lost Marie Curies") into the innovation pipeline $4^{4}$ Since exposure to innovation is uncorrelated with individuals' abilities to innovate, policies that increase exposure increase aggregate quality-weighted innovation in direct proportion to their impact on the number of inventors. This ability to attract more star inventors avoids the diminishing returns that set in

3. Jaimovich and Rebelo (2017) establish a similar result in a neoclassical model of career choice with heterogeneous abilities. Our results are consistent with theirs and make three further contributions. First, in the setting with heterogeneous abilities that they consider, we derive a formula that can be directly calibrated using the parameters and relationships we estimate empirically, namely the degree of skewness of the income distribution of inventors and the linear relationship between the social returns to innovation (as measured by citations) and inventors' incomes. Second, we also analyze the case where returns are not known at the point of career choice. Finally, we introduce exposure effects into the model.

4. Of course, one cannot conclude that aggregate welfare would be higher if these individuals were to enter innovation rather than the careers they currently pursue, as those careers may be socially valuable as well. Our point here is simply that if one takes the goal of increasing innovation as given, increasing exposure could be effective in achieving that goal. 
from running down the quality ladder of inventions when providing greater financial incentives.

It is important to keep several caveats in mind when interpreting the preceding conclusions. First, the policy impacts described above are theoretical predictions from a stylized model that matches certain empirical findings, but also rests on additional assumptions that are conventional but untested (e.g., expected utility maximization). We believe that these theoretical predictions are useful because directly identifying the impacts of taxation or other policies on career choice is very challenging. Indeed, even state-of-the-art quasi-experimental studies (e.g., Akcigit et al. 2018) identify short-run responses to financial incentives rather than long-term impacts on career choice. Nevertheless, we caution that further work is needed to gauge the empirical relevance of our results.

Second, our analysis focuses exclusively on the decisions of individual inventors. Taxes and other financial incentives could potentially affect innovation through many different channels, for instance by changing the behavior of firms, other salaried workers who contribute to the innovation process, or through general equilibrium effects (e.g., Lerner and Wulf 2007, Akcigit et al. 2017b). Taxes may also influence inventors' behavior on other margins, such as how much effort to supply or where to locate (Akcigit et al. 2016, Moretti and Wilson 2017), which are distinct from the extensive margin career choice decisions we focus on here.

Finally, our analysis does not provide guidance on specific policies to increase exposure to innovation. The fact that some neighborhoods in America induce many 
more children to become inventors suggests that it is feasible to design childhood environments that could significantly increase aggregate innovation (Bell et al. 2019). How exactly one can replicate the impacts of such environments in a cost-effective manner is a key question that we leave to future work.

The remainder of the paper is organized as follows. Section II discusses how our results contribute to the prior literature. Section III presents empirical results on inventors' career trajectories. Section IV presents the model and comparative static results on the impacts of policy changes. Section V concludes.

\section{Related Literature}

This paper contributes to the literature on financial incentives and innovation in two ways. First, most previous work studies incentives to innovate within firms, while we focus on the career choices of individuals. Second, prior work has focused primarily on "demand-side" policies such as tax credits for research and development, in contrast with our focus on "supply-side" policies that attempt to directly increase the number of inventors.

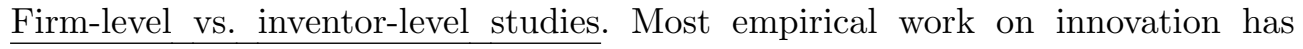
focused on firms (Griliches 1984, Hall and Rosenberg 2010), examining how innovation responds to the Intellectual Property (IP) regime or to incentives for R\&D. Most studies have found that incentives for $R \& D$ have significant effects on innovation

and R\&D expenditures (see Becker (2015) for a survey). For example, Dechezlepretre et al. (2016) and Chen et al. (2018) ) show significant impacts of changes in national 
tax rules, while Bloom et al. (2013) and Wilson (2009) find substantial effects of state-specific R\&D tax credits. Similarly, studies of direct R\&D subsidies also find positive impacts on innovation, especially for smaller firms (e.g., Howell 2017).

This focus on firms may be warranted because $R \& D$ and patenting are mainly conducted by firms, rather than by individual inventors (Mowery and Rosenberg 1991). However, important early-stage innovation sometimes still occurs outside corporations, such as the "garage" innovators responsible for many of the technological giants of today, such as Apple, Facebook, Google, and Microsoft. Moreover, it is ultimately individuals who choose whether or not to pursue careers in innovation and join firms in the innovation sector. For these reasons, it is also valuable to study the potential impacts of policies on individuals' decisions.

There has been considerable theoretical work analyzing the role of individual inventors. Indeed, most macroeconomic models of endogenous growth typically allow individuals to choose whether to join an R\&D sector or production sector (e.g., Romer 1990, Aghion and Howitt 1992, Jaimovich and Rebelo 2017). In addition, much theoretical work analyzes optimal contracts between individuals and CEOs, owner, and financiers (e.g., ?, Aghion and Tirole 1994, Manso 2011, Ederer and Manso 2013).

However, there has been much less empirical work focusing on the behavior of individual inventors because of a lack of longitudinal data that allows researchers to follow individual inventors over time. In a classic study, Schmookler (1957) obtained patent data and studied the background of 57 American inventors. This line of careful biographical work using patent data has been followed up by various papers, perhaps 
most ambitiously in the PATVAL database covering 9,017 European patents Giuri et al. 2007). Li et al. (2014) made an important step forward in this line of research by disambiguating names of inventors in order to track individuals with multiple patents over time.

Although the approach of linking together information from patent records has led to valuable research, it has important limitations. First, there is little or no biographical information on inventors (e.g., age or gender) or their backgrounds. Second, there is no capacity to track inventors' incomes or other outcomes beyond patenting. In the last few years, administrative data have enabled researchers to overcome these challenges by matching patent records to other datasets with much richer biographical information. Much of this research has been conducted using data from Scandinavian registries (e.g., Toivanen and Vaananen 2012, Lindquist et al.|2015,

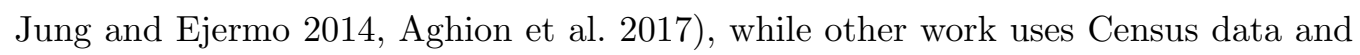
tax data from the United States Akcigit et al. 2017a, Bell et al. 2019). These studies are beginning to yield a richer understanding of the factors that affect who becomes an inventor, ranging from IQ and parental education (e.g., Aghion et al. 2017) to childhood exposure (Bell et al. 2019) and the impacts of taxation and other policy changes (Akcigit et al. 2017a, Akcigit et al. 2018).

Our empirical analysis contributes to this nascent literature by analyzing the dynamics of inventors' careers in the labor market in the United States. While some studies have presented evidence on the returns to innovation in other countries (Toivanen and Vaananen 2012, Depalo and Di Addario 2014), there is 
little contemporary information on the returns to innovation in the United States. Our empirical estimates - along with additional statistics on inventors' income distributions by year and citations that we report in our Online Data Tables - are useful in calibrating models of innovation, yielding new insights into the effects of financial incentives on inventors' behavior.

Demand-side vs. supply-side policies. Romer (2000) observes that most existing policies to increase innovation focus on the "demand" side, shifting the demand curve for innovation outward by subsidizing research and development. Romer notes that if the number of workers in the innovation sector ("supply") is fixed, then increasing demand for their skills may simply drive up their wages with no effect on the quantity of innovation, consistent with the empirical findings of Goolsbee (1998).

Given the potential limitations of demand-side policies, Romer (2000) calls for greater focus on increasing the supply of inventors directly, e.g. by increasing the number of STEM graduates (Freeman and Van Reenen 2009). Our study contributes to this agenda by directly analyzing what policies can increase the supply of inventors. Importantly, we analyze impacts not just on the total quantity of inventors but also the quality of those inventors - a feature that is critical for our conclusion that increasing childhood exposure to innovation may have larger impacts on the aggregate (quality-weighted) supply of inventors than changes in financial incentives. 


\section{Evidence on Inventors' Career Trajectories}

In this section, we present a set of empirical results on inventors' career trajectories. We begin by briefly describing the data we use for this analysis and then turn to the results.

\subsection{Data}

Sample Construction. We link data on the universe of patent applications and grants in the U.S. between 1996 and 2014 to federal income tax returns to construct a de-identified panel dataset of inventors, whom we define as patent applicants or recipients. This dataset is the same as that constructed in Bell et al. (2019), and we therefore refer readers to Section II of that paper for details regarding our data sources and sample construction.

Our analysis sample in this paper consists of all inventors who were successfully linked to the tax data, the "Full Inventors Sample" in Bell et al. (2019). 88\% of individuals who applied for or were granted a patent were successfully linked to the tax data, yielding an analysis sample of approximately 1.2 million individuals. The sample is structured as a panel from 1996 to 2012, with data in each year on individual's incomes, patents, and other variables. 
Income Definitions. We measure income as total individual income, which includes

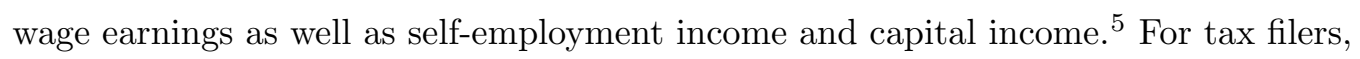
total income is defined as Adjusted Gross Income (as reported on the 1040 tax return) plus tax-exempt interest income and the non-taxable portion of Social Security and Disability benefits minus the spouse's W-2 wage earnings (for married filers). For non-filers, total income is defined simply as wage earnings as reported on form $\mathrm{W}-2$. Individuals who do not file a tax return and who have no W-2 forms are assigned an income of zero $\sqrt[6]{6}$ Because the tax data does not record W-2 income prior to 1999 , we cannot reliably measure individual earnings prior to that year, and therefore measure individuals' incomes only starting in 1999. Income is measured prior to the deduction of individual income taxes and employee-level payroll taxes in 2012 dollars, adjusting for inflation using the consumer price index (CPI-U).

Summary Statistics. Table 1 presents descriptive statistics for our analysis sample. The median number of patent applications between 1996-2012 is 1 and the median number of citations per inventor is also only 1 . But these distributions are very skewed: the standard deviations of the number of patent applications and citations are 11.1 and 118.1, respectively. The mean age of inventors is 44 and $13 \%$ of inventors in the sample are women.

5. Wage earnings comprise $95 \%$ of total income for the average inventor (conditional on having total income above $\$ 1,000)$.

6. Importantly, these observations are true zeros rather than missing data. Because the database covers all tax records, we know that these individuals have no taxable income. 


\subsection{Empirical Results}

We now use these data to examine inventors' career paths and outcomes after they enter labor market. We establish four facts on the income distributions of inventors that are both of interest in their own right and shed light on the effects of financial incentives on innovation when interpreted using a standard model of career choice.

Fact 1: Returns to Innovation are Highly Skewed. We begin by characterizing the cross-sectional distribution of inventors' permanent incomes. We measure inventors' permanent incomes by computing their average annual incomes between the ages of 40 and 50. Since our data on individual incomes begin in 1999 and end in 2012, we focus on individuals in our analysis sample who are born between 1959 and 1962, for whom we see income at all ages between 40 and 50. These individuals applied for or were granted patents between ages 34 and 53, as our patent data span 1996-2012.

The income distribution of inventors, plotted in Figure 1A, is extremely skewed. The median annual income between ages 40-50 (in 2012 dollars) is $\$ 114,000$, the mean is $\$ 192,000$, and the 99 th percentile is $\$ 1.6$ million. $22 \%$ of total income earned by inventors accrues to individuals in the top $1 \%$ of the inventors' income distribution, a top income share that is similar to the $23 \%$ top income share in the mid-2000s in the population as a whole (Atkinson et al. 2011). The degree of inequality among inventors is similar to that in the general population. In contrast, most other highskilled professions, such as medicine or law, have much more homogeneous income distributions; one of the only other professions with comparable heterogeneity in

income is the financial sector (Lockwood et al. 2017). Innovation thus differs from 
many other high-skilled occupations in that a small group of individuals obtain a large fraction of the returns.

Fact 2: Private Returns are Highly Correlated with Social Returns. Inventor's incomes reflect the private returns to innovation, which may differ from social returns. Prior work has used the future citations to a patent as a measure of its scientific impact and social value (e.g., Jaffe et al. 1993). Figure 1B shows that the private returns to patents are highly correlated with their scientific impact, as measured by citations. It presents a binned scatter plot of average annual income between ages 40-50 vs. the total number of citations an inventor obtains. We restrict the sample to patent applications in 1996 in this figure to maximize the time horizon over which we can measure future citations. The figure is constructed by dividing citations into 21 bins and plotting mean income vs. mean citations within each bin. The first 19 bins include inventors in the first 19 ventiles ( $5 \%$ bins) of the citations distribution, while the last two bins plot the same relation for the 95th to 98th percentiles and the 99th percentile of the citation distribution. There is a strong positive relationship between citations and income. Notably, inventors who have patents in the top $1 \%$ of the citation distribution earn more than $\$ 1$ million per year between ages 40 and 50, showing that individuals with highly impactful innovations from a scientific perspective obtain large private returns over their lifetimes.

Having characterized the cross-sectional distribution of inventors' incomes, we now turn to the dynamics of innovation and income over inventors' careers. 
Fact 3: Innovation Rates Peak in Mid-Career. Figure 2A plots the cross-sectional age distribution of individuals who filed a patent application in 2000 that was subsequently granted. The modal age of patenting is 38 , with symmetric declines at younger and older ages, consistent with Jones et al. (2014). This pattern is partly driven by the fact that the fraction of people who work falls at older ages. Figure $2 \mathrm{~B}$ plots the fraction of workers in the population (individuals with positive $\mathrm{W}-2$ earnings) who patent in 2000 by age. Innovation per worker still peaks around 40, but falls more gradually at older ages, with a $33 \%$ decline from age 40 to 60 . Figure $2 \mathrm{C}$ plots the fraction of workers whose patents went on to become highly-cited (in the top $5 \%$ of patents filed in 2000) by age. The rate of high-impact innovation falls by $66 \%$ from age 40 to 60 . This result is broadly consistent with Acemoglu et al.'s (2014) hypothesis that the "young and restless" have higher impact discoveries, although individuals' most impactful innovations tend to come in the middle rather than at the beginning of their professional careers.

Fact 4: Most Returns are Accrued Before Patents are Granted. Finally, we examine the dynamics of income over inventors' careers. Figure 3A plots the median income of individuals who apply for a patent at age 30,40 , or 50 . In each case, we see a steep increase in income in the years immediately preceding the patent application, following by a leveling off or decline. Figure 3B generalizes this analysis using an event study framework, defining year 0 as the year in which an individual files a patent application and other years relative to this reference year (e.g., +1 is the year 
after the application) 7 Consistent with the findings in Figure 3A, median and mean incomes rise sharply and peak at the point of patent application, similar to Depalo and Di Addario's (2014) findings in Italian data. We also find a similar trajectory in the upper tail: the 99 th percentile of the distribution peaks at $\$ 1.8$ million shortly after the year of application and falls slightly thereafter.

Figure 3C presents event studies of median income for three groups: unsuccessful applications (patents that were not granted before 2014), all granted patents, and highly-cited patents (those in the top $5 \%$ of the citation distribution among all patents granted in the same year). As noted above, individuals with highly-cited patents have higher incomes, and much of that higher income again comes from a much steeper earnings trajectory in the years prior to the point of patent application. The results in Figure 3 suggest that a patent application marks the peak of a successful career in innovation rather than an event that itself produces high returns, perhaps because the patent event itself is not news to the firm or the market. Indeed, patent royalties account for less than $3 \%$ of income even for inventors with highly cited patents five years after a patent is granted 8

In summary, the private returns to innovation are highly skewed and correlated with their scientific impact. In addition, returns may be uncertain at the time of

7. We limit the sample to individuals who file patent applications between ages 35 and 50 . For individuals who file multiple patents in this age window, we choose one of the patents at random.

8. Of course, some very high value patents may have significant causal impacts on the wages of an inventor and her co-workers (?, Kline et al. 2017). 
career choice, as the most impactful inventions tend to occur around age 40, and incomes tend to rise rapidly only shortly before that point. In the next section, we show that these facts imply that changes in financial incentives are unlikely to have large effects on rates of innovation in standard models of career choice.

\section{A Model of Inventors' Careers}

In this section, we develop a model of inventor career choice that broadly matches the empirical findings above as well as the evidence on the importance of childhood exposure effects in determining whether individuals pursue a career in innovation from Bell et al. (2019). Our model builds on recent models of innovation and career choice (e.g. Hsieh et al. 2016, Jaimovich and Rebelo 2017) in two ways. First, we introduce a role for exposure, whereby some people do not consider a career in innovation irrespective of incentives, e.g., because of a lack of awareness. Second, we allow for the possibility that the returns to innovation may be partly uncertain to the individual at the point of career choice in light of our findings above on the earnings trajectories of inventors.

We first describe the setup of the model and then present comparative static results on the effects of changes in financial incentives and exposure to innovation. Derivations and proofs are given in the Appendix. 


\subsection{Model Setup}

A continuum of agents, indexed by $i$ (with total mass one), choose to enter one of two sectors: the innovation sector $(I)$ or another sector $(\bar{I})$. There are three factors that govern each agent's choice of occupation: financial payoffs, exposure, and preferences.

Financial Payoffs. Outside the innovation sector, agents receive a fixed wage $w_{\bar{I}}$. In the innovation sector, agents' payoffs are determined by their innovationspecific abilities $\alpha_{i} \geq 1$, which follow a Pareto distribution $F_{\alpha}(\alpha)=1-(1 / \alpha)^{\beta_{\alpha}}$, and a stochastic shock $\pi_{i} \geq 1$ that is independently drawn from a different Pareto distribution $F_{\pi}(\pi)=1-(1 / \pi)^{\beta_{\pi}}$. The Pareto shape parameters $\beta_{\pi} \geq 1$ and $\beta_{\alpha} \geq 1$ govern the skewness of the payoffs. Agents know their ability $\alpha_{i}$ when deciding whether or not to enter the innovation sector but do not know $\pi_{i} 9^{9}$ Agent $i$ 's realized payoff from entering the innovation sector is given by the product of ability and the stochastic shock:

$$
r_{i} \equiv \alpha_{i} \cdot \frac{\beta_{\alpha}-1}{\beta_{\alpha}} \cdot \pi_{i} \frac{\beta_{\pi}-1}{\beta_{\pi}}
$$

With this specification, changes in the shape parameters $\beta_{\pi}$ and $\beta_{\alpha}$ affect the skewness of payoffs while leaving the mean return $E\left[r_{i}\right]$ unchanged. The skewness of the payoffs is decreasing in the shape parameters; when the shape parameters approach one, the

9. The stochastic returns $\pi_{i}$ can be interpreted either as the inherently stochastic component of financial rewards to innovation (e.g., an invention may be a commercial success or failure due to many factors), or as the component of an inventor's ability which is revealed ex-post (after choosing an inventor career) and could not be anticipated ex-ante (before career choice). 
distribution of payoffs becomes infinitely skewed. We assume that wages and returns to innovation are fixed, and in particular do not respond to the number of individuals who enter each sector.

Individuals must pay a tax $\tau$ on their incomes in the innovation sector, resulting in a net-of-tax payoff to innovation of $(1-\tau) r_{i}$ This tax $\tau$ can equivalently be interpreted as a cost of entering innovation, as in Hsieh et al. (2016) 11

Exposure. Individuals' decisions are influenced by whether they are exposed to innovation. We model exposure as a binary variable $\lambda_{i}$ that follows a Bernoulli distribution $\lambda_{i} \sim B(\lambda)$. Individuals who do not receive exposure to innovation $\left(\lambda_{i}=0\right)$ never pursue innovation, while those who receive exposure $\left(\lambda_{i}=1\right)$ choose their sector by maximizing expected lifetime utility.

Importantly, we assume that the probability of exposure to innovation is uncorrelated with individuals' abilities to innovate. This assumption is motivated by evidence from Bell et al. (2019) that individuals who are less exposed to innovation

10. We assume that the tax applies only to the innovation sector as a simple way to capture the fact that top income tax rates may affect the payoffs to innovation (which can sometimes be very high) more than payoffs to other careers that have lower (fixed) salaries. Insofar as taxes also affect payoffs in other sectors, career choices will be less sensitive to tax rates, reinforcing our results below.

11. In Hsieh et al.'s model, the barriers to entry $\tau$ vary across subgroups (e.g., women and minorities effectively face higher tax rates). Our model can be interpreted as applying to one such subgroup; the comparative static results below show how differences in $\tau$ affect innovation rates across subgroups. 
- e.g., women, minorities, and children from low-income families - do not appear to have different latent abilities to innovate, as measured for instance by their math test scores early in childhood.

Preferences. To obtain closed-form solutions, we assume that agents have constant relative risk aversion (CRRA) utility functions, although all of the qualitative results that follow hold with any smooth and concave utility function. Let $u\left(c_{i}\right)=c_{i}^{1-\theta} /(1-$ $\theta$ ) denote agent $i$ 's utility as a function of consumption $c_{i}$, with $\theta \geq 0$.

\subsection{Agent Behavior}

We now characterize agents' career choices and aggregate innovation rates.

Working in the innovation sector yields expected utility $V_{i}^{I}=E_{\pi}\left[u\left(r_{i} \cdot\left(1-\tau_{i}\right)\right)\right]$. Agent $i$ therefore enters the innovation sector if $\lambda_{i} V_{i}^{I}>V_{i}^{\bar{I}}=u\left(w_{\bar{I}}\right)$. It is straightforward to show that agents follow a threshold rule when deciding whether to enter innovation: there is an ability threshold $\bar{\alpha}$ such that all agents with innovationspecific ability $\alpha_{i}>\bar{\alpha}$ enter the innovation sector. Taking into account exposure effects, the share of agents who become inventors is therefore

$$
\varphi=\lambda \cdot\left(1-F_{a}(\bar{\alpha})\right)
$$

We show in the appendix that under our functional form assumptions, we can obtain a closed-form expression for the share of inventors:

$$
\varphi=\kappa_{\varphi} \cdot \lambda(1-\tau)^{\beta_{\alpha}}
$$


where

$$
\kappa_{\varphi}=\left(\frac{\beta_{\pi}-1}{w_{\bar{I}} \beta_{\pi}} \frac{\beta_{\alpha}-1}{\beta_{\alpha}}\right)^{\beta_{\alpha}}\left(\frac{\beta_{\pi}}{\beta_{\pi}+\theta-1}\right)^{\frac{\beta_{\alpha}}{1-\theta}} \geq 0
$$

Given the evidence in Figure 1B above that inventors' salaries are proportional to their patent citations on average, we assume that the social value of innovation is $s_{i}=\nu \cdot r_{i}$, where $\nu>0$. We define aggregate quality-weighted innovation as

$$
\Phi=\varphi E\left[\nu \cdot r_{i} \mid \alpha_{i}>\bar{\alpha}\right]
$$

Intuitively, aggregate innovation depends upon the number of inventors $(\varphi)$ and the average quality of their innovations. Again, we can obtain a closed-form expression for aggregate innovation:

$$
\Phi=\kappa_{\Phi} \cdot \lambda(1-\tau)^{\beta_{\alpha}-1}
$$

where

$$
\kappa_{\Phi}=\nu\left(\frac{\beta_{\pi}-1}{w_{\bar{I}} \beta_{\pi}} \frac{\beta_{\alpha}-1}{\beta_{\alpha}}\right)^{\beta_{\alpha}-1}\left(\frac{\beta_{\pi}}{\beta_{\pi}+\theta-1}\right)^{\frac{\beta_{\alpha}-1}{1-\theta}} \geq 0
$$

In the next two subsections, we characterize how changes in tax rates $(\tau)$ and exposure $(\lambda)$ affect $\varphi$ and $\Phi$. 


\subsection{Effects of Changes in Financial Payoffs}

The following proposition characterizes the impact of reducing the tax rate $\tau$ (which can be interpreted as an increase in the financial return to innovation or as a reduction in barriers to entry) on innovation.

Proposition 1. Reducing the tax rate $(\tau)$ increases the fraction of inventors $(\varphi)$ and aggregate innovation $(\Phi)$.

The magnitude of the response is characterized by three properties:

1. [Exposure dampening] The absolute impact of changes in $\tau$ on $\varphi$ and on $\Phi$ are proportional to exposure $\lambda$.

2. [Forecastable returns] When returns to innovation vary purely because of heterogeneity in ability known at time of career choice $\left(\beta_{\pi} \rightarrow \infty\right)$, the elasticities of $\varphi$ and $\Phi$ with respect to $(1-\tau)$ converge to $\varepsilon_{\varphi,(1-\tau)} \rightarrow \beta_{\alpha}$ and $\varepsilon_{\Phi,(1-\tau)} \rightarrow$ $\beta_{\alpha}-1$. As the skewness of the ability distribution increases $\left(\beta_{a} \rightarrow 1\right)$, the elasticity of $\Phi$ with respect to $(1-\tau)$ converges to zero.

3. [Stochastic returns] As the skewness of stochastic returns to innovation increases $\left(\beta_{\pi} \rightarrow 1\right)$, at a given initial level of innovation $\varphi_{0}$, the elasticities of $\varphi$ and $\Phi$ with respect to $(1-\tau)$ both converge to zero if $\theta>0: \varepsilon_{\varphi,(1-\tau)} \rightarrow 0$ and $\varepsilon_{\Phi,(1-\tau)} \rightarrow 0$.

The first result in Proposition 1 (exposure dampening) implies that the response of the number of inventors (and in turn of aggregate innovation) to changes in financial incentives is muted when exposure to innovation is low. Naturally, only the agents who are exposed to innovation respond to a change in $\tau$. Given Bell et al.'s (2019) 
evidence that rates of innovation are low in many subgroups of the population because of a lack of exposure, this result implies that changes in financial incentives may have very muted effects on the number of inventors. 12

The second result in Proposition 1 (forecastable returns) focuses on the case where heterogeneity in inventors' incomes is driven entirely by known differences in abilities rather than stochastic shocks. In this case, the elasticity of aggregate innovation $\Phi$ with respect to changes in financial returns is determined purely by the skewness of the distribution of innovation abilities. The elasticity falls as the skewness of the ability distribution rises $\left(\beta_{\alpha} \rightarrow 1\right)$ because there are fewer individuals who are on the margin of entering the innovation sector, whose decisions would be influenced by small tax changes. Moreover, aggregate quality-weighted innovation $(\Phi)$ is less responsive to changes in the tax rate $\tau$ than the number of agents entering innovation $(\varphi)$, as shown by Jaimovich and Rebelo (2017). Intuitively, the marginal entrants who enter the innovation sector because of a reduction in the tax rate $\tau$ must have lower ability than the average inventor already in the sector, thereby increasing quality-weighted innovation by less than the total number of inventors. As the ability distribution becomes more skewed $\left(\beta_{\alpha} \rightarrow 1\right)$, the elasticity of quality-weighted innovation with respect to the tax rate converges to zero. In the limiting case, aggregate innovation

12. Although the absolute impacts of tax changes $(d \varphi / d \tau$ and $d \Phi / d \tau)$ are proportional to exposure $\lambda$, the elasticities of $\varphi$ and $\Phi$ with respect to $\tau$ are invariant to $\lambda$. A lower value of $\lambda$ reduces the rate of initial innovation at the same rate as the derivatives, leaving the elasticity (percentage impacts) unchanged. 
is driven by a small fraction of star inventors whose behavior is insensitive to taxes because they have very high earnings in the innovation sector relative to the outside option.

Figure $4 \mathrm{~A}$ illustrates this result by plotting the number of inventors $\varphi$ and qualityweighted innovation $\Phi$ as a function of the tax rate on inventors' earnings. In this simulation, we set $\beta_{\pi}=\infty$ (no stochastic shocks) and the skewness of the ability distribution $\beta_{\alpha}=1.26$ to match the Pareto shape parameter of 1.26 estimated using the inventors' empirical earnings distribution shown in Figure 1. Both $\varphi$ and $\Phi$ are normalized to $100 \%$ at a tax rate of $\tau=0$. As predicted by the proposition, the number of inventors declines much faster than total innovation as the tax rate on inventors' earnings increases. For example, at a tax rate of $\tau=40 \%$ on inventors' earnings, the total number of inventors $\varphi$ is $48 \%$ smaller than it would be in the absence of taxes $(\tau=0)$, but aggregate quality-weighted innovation $\Phi$ is only depressed by $12.5 \%$. While the exact numbers naturally depend upon model specification, these calculations suggest that aggregate quality-weighted innovation may not be very sensitive to small changes in tax rates under parameters that match the empirical distribution of inventors' incomes.

The third result in Proposition 1 (stochastic returns) focuses on the case where heterogeneity in inventors' incomes is driven primarily by unforecastable shocks rather than known ability heterogeneity, i.e. where $\beta_{\pi} \rightarrow 1$. The level of innovation $\varphi$ converges to 0 as $\beta_{\pi} \rightarrow 1$ when $\theta>0$ because the expected value of innovation $V_{I}$ falls to 0 as the variance of payoffs grows large, holding the mean payoff fixed, 
when individuals are risk averse. To obtain comparative statistics at the same level of innovation $\varphi_{0}$ as in the case with pure ability heterogeneity analyzed above, we reduce the wage in the non-innovation sector $w_{\bar{I}}$ as $\beta_{\pi} \rightarrow 1$ to keep the fraction of inventors fixed at $\varphi_{0} 13$

In this setting, as the skewness of stochastic shocks rises, both the elasticities of the number of inventors and quality-weighted innovation with respect to tax rates converge to zero if agents are risk averse $(\theta>0)$. The logic underlying this result is easiest to understand in the context of a limiting example with two states of the world: a bad state in which innovation has zero return and a good state in which innovation has a large payoff, say $\$ 10$ million. In the bad state, taxes have no impact on utility. In the good state, a slightly smaller payout (e.g., $\$ 9$ million instead of $\$ 10$ million) does not reduce an agent's incentive to become an inventor by very much because the marginal utility of consumption is already low this far out in the income distribution. Intuitively, when returns are very skewed, taxes only affect inventors' payoffs when they are very deep in the money and are not sensitive to financial incentives, resulting in small behavioral responses. Put differently, when innovation has very risky payoffs, inventors must enter innovation partly because of its non-monetary benefits, making their behavior less sensitive to financial incentives.

13. Formally, we change $w_{\bar{I}}$ to $\kappa\left(\beta_{\pi}\right) \cdot w_{\bar{I}}$ as we vary $\beta_{\pi}$, choosing the scaling factor $\kappa$ to keep the fraction of inventors at $\varphi_{0}$, which one can interpret as a fixed (empirically observed) level of innovation. See Appendix for further details. 
Figure $4 \mathrm{~B}$ illustrates this result by plotting innovation rates vs. taxes when the heterogeneity in inventors' incomes is driven primarily by stochastic shocks rather than differences in ability. We calibrate the model so that stochastic returns account for $90 \%$ of the skewness in inventors' earnings and the income distribution has a Pareto shape parameter of 1.26 as above ${ }^{14}$ We consider two cases: $\theta=0$ (risk neutral agents, linear utility) and $\theta=1$ (risk averse agents, log utility). With linear utility, taxes have very large effects: a tax rate of $\tau=40 \%$ reduces quality-weighted innovation $\Phi$ by $70.5 \%$ relative to the benchmark with no taxes. But when agents are risk averse, taxes have modest effects: $\Phi$ falls by only $9.4 \%$ from the no-tax benchmark when $\tau=40 \%$. These calculations suggest that tax changes are likely to have modest effects on aggregate innovation even when the returns to innovation are uncertain, under the standard assumption that individuals have diminishing marginal utilities of consumption.

In sum, Proposition 1 implies that the decisions of individuals who contribute most to aggregate innovation are unlikely to be very sensitive to small changes in financial incentives in canonical models of career choice that match our empirical findings regarding the skewness of inventors' incomes and the correlation between

14. Formally, we set $\beta_{\pi}$ and $\beta_{\alpha}$ such that $s \equiv\left(\left(\beta_{\pi} / \beta_{\pi}-1\right)-1\right) /\left(\left(\beta_{\alpha} / \beta_{\alpha}-1\right)-1+\left(\beta_{\pi} / \beta_{\pi}-1\right)-1\right)=$ 0.9 and the equilibrium income distribution has a shape parameter of 1.26 . We retain $10 \%$ of skewness from variation in ability because the model is degenerate if we only allow for heterogeneity from stochastic shocks, since there is no source of ex-ante heterogeneity across agents other than ability in our model. 
private and social returns. Importantly, the second and third results in Proposition 1 show that this conclusion holds regardless of whether the returns to innovation are known at the point of career choice or not.

\subsection{Effects of Changes in Exposure}

We now contrast the impact of changes in financial incentives with the impact of changes in exposure $(\lambda)$ on rates of innovation.

Proposition 2. The elasticities of the number of inventors and aggregate innovation with respect to exposure $\lambda$ are both equal to one: $\varepsilon_{\Phi, \lambda}=\varepsilon_{\varphi, \lambda}=1$.

Proposition 2 shows that, unlike the impact of changes in financial payoffs, the impact of changing exposure is invariant to the skewness of the distribution of inventors' earnings or other parameters of the model. Increasing exposure simply scales up the fraction of individuals who enter innovation. For instance, increasing $\lambda$ from $10 \%$ to $20 \%$ mechanically doubles the (randomly selected) set of individuals who are exposed to and enter the innovation sector. This doubles aggregate qualityweighted innovation as well given our assumption that exposure is uncorrelated with individuals' abilities to innovate.

Proposition 2 implies that there may be great potential to increase aggregate innovation by increasing exposure in a subgroup $g$ that currently has few inventors if the low rate of innovation $\varphi_{g}$ in that group is due to a lack of exposure (in which case there is scope to increase $\lambda_{g}$ ) rather than high barriers to entry $\tau_{g}$. One way to 
determine whether the low innovation rate is driven by exposure effects or barriers to entry is by examining the average quality of inventions for inventors in that subgroup. The following corollary formalizes this result:

COROLLARY 1. If the distribution of innovation abilities does not vary across groups, differences in the average quality of inventions reveal whether differences in innovation rates arise from barriers to entry or exposure effects.

1. [Barriers to entry] Groups that face higher barriers to entry $\tau$ have higher-quality inventions conditional on inventing: $\varphi$ declines with $\tau$, while $E\left[\nu \cdot r_{i} \mid \alpha_{i}>\bar{\alpha}\right]$ increases with $\tau$.

2. [Exposure] Groups that have less exposure to innovation $\lambda$ have the same quality of inventions conditional on inventing: $\varphi$ declines with $\lambda$, but $E\left[\nu \cdot r_{i} \mid \alpha_{i}>\bar{\alpha}\right]$ does not vary with $\lambda$.

The first result in this corollary follows from the logic in the second part of Proposition 1. The marginal inventor who is screened out as barriers to entry rise is of lower quality than the average inventor. The inventors who remain in groups that face high costs of entering innovation thus have higher quality patents on average. The second result follows from the logic underlying Proposition 2. Since an increase in exposure simply draws in randomly selected inventors, groups that have less exposure do not have inventors of different quality on average.

Bell et al. (2019, Figure XI) show that in practice, individuals from underrepresented groups - e.g., children from low-income families, women, and minorities 
- who become inventors do not have higher-quality patents on average, as measured by their citations per patent or incomes. Based on Corollary 1, these findings are consistent with the hypothesis that the low rates of innovation among certain groups are driven primarily by a lack of exposure rather than fixed costs of entry that screen out inventors of marginal quality, as in Hsieh et al. (2016). Put differently, subgroups with few inventors are just as under-represented among "star" inventors as they are among inventors as a whole. Hence, there may be substantial scope to increase aggregate innovation by increasing exposure among such groups; indeed, Bell et al. (2019) find that the number of inventors in the U.S. would quadruple if women, minorities, and children from low-income families were to invent at the same rate as white men from high-income families.

\section{Conclusion}

Developed countries typically provide substantial financial incentives to spur innovation through R\&D tax credits and direct grants. Indeed, the potential for higher rates of innovation and entrepreneurship is frequently cited as an argument for reductions in top income tax rates. In this paper, we studied the impacts of financial incentives on one important margin that contributes to aggregate innovation: the supply of inventors. Using new panel data covering virtually all inventors in the U.S. from 1996-2012, we first showed that the private returns to innovation (measured by inventors' incomes in tax records) are extremely skewed, highly correlated with their scientific impact, and are often largest in the middle of individuals' careers. 
We then constructed a stylized model of career choice that matches these facts as well as evidence from our companion paper (Bell et al. 2019) showing that childhood exposure to innovation plays a critical role in determining whether individuals become inventors.

Our model predicts that financial incentives have limited potential to increase aggregate innovation because (i) they only affect individuals who are exposed to innovation and (ii) they have no impact on the decisions of star inventors who matter most for aggregate innovation, because the private financial returns to high-impact innovations are already quite large. Although lower income tax rates do increase the number of inventors, their impact on aggregate (quality-weighted) innovation is likely to be quantitatively small. In contrast, increasing exposure to innovation could have substantial impacts on innovation by drawing more star inventors ("Einsteins") into the field.

Our analysis implies that the neoclassical models of career choice that are widely used in the innovation and growth literatures cannot generate large elasticities of quality-weighted inventor supply with respect to financial incentives when they are calibrated to match empirical evidence on the returns to innovation. This result points to two directions for further work: more careful assessment of the impacts of financial incentives and consideration of alternative policies to increase the supply of innovation. 
In the context of financial incentives, it would be useful to test the predictions of our model regarding career choice decisions, perhaps by building on recent quasiexperimental studies of taxes and innovation (e.g., Moretti and Wilson 2017, Akcigit et al. 2018). Such analyses would both shed light on the empirical relevance of our predictions and elucidate how standard models of career choice must be modified to fit the empirical findings. In particular, if taxes affect rates of innovation significantly, they may do so through other mechanisms beyond career choice, such as the behavior of inventors within firms, agglomeration patterns, or general equilibrium effects.

A second natural direction for future work is to explore other policies to increase the supply of inventors beyond financial incentives. We focused here on one such possibility: increasing exposure to innovation during childhood. Changes in exposure could have substantial effects: for instance, Bell et al. (2019) estimate that moving a child from a metropolitan area that is at the 25th percentile of the distribution in terms of inventors per capita to the 75 th percentile would increase a child's probability of becoming an inventor by $37 \%$. Developing feasible policies that could provide such exposure without having to move families would be very valuable. More broadly, identifying policies that escape the diminishing marginal returns of financial incentives by drawing star inventors into the innovation pipeline - whether through exposure, human capital investments, or other interventions - could greatly increase the supply of innovation. 


\section{Appendix: Derivations and Proofs}

In this appendix, we first present analytical formulas for the key expressions in our model, then describe the comparative statics of interest, and finally present proofs of the propositions in Section IV.

Analytical Formulas. Expected utility in the innovation sector for agent $i$ is given by:

$$
\begin{aligned}
V_{i}^{I} & =\int_{1}^{\infty} \frac{\left((1-\tau) \cdot \frac{\beta_{\pi}-1}{\beta_{\pi}} x \cdot \frac{\beta_{\alpha}-1}{\beta_{\alpha}} \alpha_{i}\right)^{1-\theta}}{1-\theta} d F_{\pi}(x) \\
& =\frac{\beta_{\pi}}{\beta_{\pi}+\theta-1}\left(\frac{\beta_{\pi}-1}{\beta_{\pi}}\right)^{1-\theta} \frac{\left((1-\tau) \cdot \frac{\beta_{\alpha}-1}{\beta_{\alpha}} \alpha_{i}\right)^{1-\theta}}{1-\theta}
\end{aligned}
$$

Since $\partial V_{i}^{I} / \partial \alpha_{i}>0$ and the outside wage is fixed, there is an ability cutoff beyond which all agents enter the innovation sector. This cutoff is characterized by:

$$
\begin{aligned}
V^{\bar{I}} & =V_{\bar{\alpha}}^{I} \\
\Rightarrow \frac{\left(w_{\bar{I}}\right)^{1-\theta}}{1-\theta} & =\frac{\beta_{\pi}}{\beta_{\pi}+\theta-1}\left(\frac{\beta_{\pi}-1}{\beta_{\pi}}\right)^{1-\theta} \frac{\left((1-\tau) \cdot \frac{\beta_{\alpha}-1}{\beta_{\alpha}} \bar{\alpha}\right)^{1-\theta}}{1-\theta} \\
\Rightarrow \bar{\alpha} & =\frac{w_{\bar{I}}}{1-\tau} \frac{\beta_{\pi}}{\beta_{\pi}-1} \frac{\beta_{\alpha}}{\beta_{\alpha}-1}\left(\frac{\beta_{\pi}+\theta-1}{\beta_{\pi}}\right)^{\frac{1}{1-\theta}}
\end{aligned}
$$

It follows that the fraction of agents entering the innovation sector is:

$$
\varphi=\lambda \cdot\left(1-F_{\alpha}(\bar{\alpha})\right)=\lambda \cdot\left(\frac{1-\tau}{w_{\bar{I}}}\right)^{\beta_{\alpha}}\left(\frac{\beta_{\pi}-1}{\beta_{\pi}} \frac{\beta_{\alpha}-1}{\beta_{\alpha}}\right)^{\beta_{\alpha}}\left(\frac{\beta_{\pi}}{\beta_{\pi}+\theta-1}\right)^{\frac{\beta_{\alpha}}{1-\theta}} .
$$

Aggregate innovation is given by

$$
\begin{aligned}
\Phi & =\nu \frac{\beta_{\pi}-1}{\beta_{\pi}} \frac{\beta_{\alpha}-1}{\beta_{\alpha}} \lambda \int_{\bar{\alpha}}^{\infty} x d F_{\alpha}(x) \int_{1}^{\infty} y d F_{\pi}(y) \\
& =\lambda \cdot \nu\left(\frac{\beta_{\pi}-1}{\beta_{\pi}} \frac{\beta_{\alpha}-1}{\beta_{\alpha}}\right)^{\beta_{\alpha}-1}\left(\frac{1-\tau}{w_{\bar{I}}}\right)^{\beta_{\alpha}-1}\left(\frac{\beta_{\pi}}{\beta_{\pi}+\theta-1}\right)^{\frac{\beta_{\alpha-1}}{1-\theta}}
\end{aligned}
$$

The expected quality of innovations conditional on inventing is:

$$
E\left[\nu \cdot r_{i} \mid \alpha_{i}>\bar{\alpha}\right]=\frac{\Phi}{\varphi}=\nu \frac{\beta_{\alpha}}{\beta_{\alpha}-1} \frac{\beta_{\pi}}{\beta_{\pi}-1} \frac{w_{\bar{I}}}{1-\tau}\left(\frac{\beta_{\pi}+\theta-1}{\beta_{\pi}}\right)^{\frac{1}{1-\theta}}
$$

Comparative Statics. Our goal is to compute elasticities of innovation with respect to tax rates in two scenarios, holding fixed the fraction of inventors at a given (empirically observed) level: (a) the case where $\beta_{\pi} \rightarrow \infty$ (i.e., there are no stochastic 
shocks) and (b) the case where $\beta_{\pi} \rightarrow 1$ (i.e., the skewness of stochastic shocks grows arbitrarily large).

In the first case, we simply compute the elasticities of $\varphi$ and $\Phi$ with respect to the net-of-tax rate $1-\tau$ around the level of innovation $\varphi_{0}$ that prevails when $\beta_{\pi} \rightarrow \infty$. Using equations (7) and (8), these elasticities are:

$$
\begin{gathered}
\varepsilon_{\varphi,(1-\tau)}=\frac{d \varphi}{d(1-\tau)} \frac{1-\tau}{\varphi}=\beta_{\alpha}, \\
\varepsilon_{\Phi,(1-\tau)}=\frac{d \Phi}{d(1-\tau)} \frac{1-\tau}{\Phi}=\beta_{\alpha}-1 .
\end{gathered}
$$

In the second case, the level of innovation $\varphi$ converges to 0 as $\beta_{\pi} \rightarrow 1$ when $\theta>0$ because the expected value of innovation $V_{I}$ falls to 0 as the variance of payoffs grows large holding the mean payoff fixed. To obtain comparative statistics that are comparable to the first case, we hold the fraction of inventors fixed at $\varphi_{0}$ (the same level as in the first case) by varying the wage in the non-innovation sector $w_{\bar{I}}$ as $\beta_{\pi} \rightarrow 1$. In particular, we change $w_{\bar{I}}$ to $\kappa\left(\beta_{\pi}\right) \cdot w_{\bar{I}}$ as we vary $\beta_{\pi}$, choosing the scaling factor $\kappa$ to keep the fraction of inventors at $\varphi_{0}$ as a function of $\beta_{\pi}$. Formally, for a given change in skewness from a reference level $\beta_{\pi}^{B}$ to the level of interest $\beta_{\pi}, \kappa\left(\beta_{\pi}\right)$ is chosen such that the threshold to enter innovation $\bar{\alpha}\left(\beta_{\pi}, \kappa\right)=\bar{\alpha}\left(\beta_{\pi}^{B}\right)$, i.e.

$$
\kappa\left(\beta_{\pi}\right)=\frac{\beta_{\pi}-1}{\beta_{\pi}} \frac{\beta_{\pi}^{B}}{\beta_{\pi}^{B}-1}\left(\frac{\beta_{\pi}}{\beta_{\pi}+\theta-1} \frac{\beta_{\pi}^{B}+\theta-1}{\beta_{\pi}^{B}}\right)^{\frac{1}{1-\theta}} .
$$

At any given level of $\beta_{\pi}$, the elasticity of innovation with respect to the net-of-tax rate around the original fraction of inventors $\varphi_{0}$ is:

$$
\varepsilon_{\varphi,(1-\tau)}=\frac{d \varphi}{d(1-\tau)} \frac{1-\tau}{\varphi \cdot\left(\frac{1}{\kappa}\right)^{\beta_{\alpha}}}=\beta_{\alpha} \cdot \kappa\left(\beta_{\pi}\right)^{\beta_{\alpha}} .
$$

When the reference level of skewness $\beta_{\pi}^{B} \rightarrow \infty$ (i.e., when $w_{\bar{I}}$ is adjusted to hold the fraction of inventors fixed at $\varphi_{0}$ ), the elasticity of innovation w.r.t. $1-\tau$ is:

$$
\varepsilon_{\varphi,(1-\tau)}=\beta_{\alpha}\left(\frac{\beta_{\pi}-1}{\beta_{\pi}}\right)^{\beta_{\alpha}}\left(\frac{\beta_{\pi}}{\beta_{\pi}+\theta-1}\right)^{\frac{\beta_{\alpha}}{1-\theta}}
$$

Likewise, the elasticity of aggregate innovation $(\Phi)$ w.r.t. the net of tax rate $(1-\tau)$ is:

$$
\varepsilon_{\Phi,(1-\tau)}=\frac{d \Phi}{d(1-\tau)} \frac{1-\tau}{\Phi \cdot(\kappa)^{1-\beta_{\alpha}}}=\left(\beta_{\alpha}-1\right)\left(\frac{\beta_{\pi}-1}{\beta_{\pi}}\right)^{\beta_{\alpha}-1}\left(\frac{\beta_{\pi}}{\beta_{\pi}+\theta-1}\right)^{\frac{\beta_{\alpha-1}}{1-\theta}}
$$

Propositions. With these expressions in hand, it is straightforward to establish the propositions and corollaries in Section 4. 
Proof of Proposition 1. (7) and (12) imply

$$
\frac{d \varphi}{d(1-\tau)}=\lambda \cdot \frac{\beta_{\alpha}\left(1-F_{\alpha}\left(\overline{\alpha_{0}}\right)\right)\left(\frac{\beta_{\pi}}{\beta_{\pi}-1}\right)^{\beta_{\alpha}}\left(\frac{\beta_{\pi}+\theta-1}{\beta_{\pi}}\right)^{\frac{\beta_{\alpha}}{1-\theta}}}{1-\tau}
$$

(8) and (12) imply

$$
\frac{d \Phi}{d(1-\tau)}=\lambda \cdot \frac{\left(\beta_{\alpha}-1\right)\left(1-F_{\alpha}\left(\overline{\alpha_{0}}\right)\right)^{\frac{\beta_{\alpha}-1}{\beta_{\alpha}}}\left(\frac{\beta_{\pi}}{\beta_{\pi}-1}\right)^{\beta_{\alpha}-1}\left(\frac{\beta_{\pi}+\theta-1}{\beta_{\pi}}\right)^{\frac{\beta_{\alpha}-1}{1-\theta}}}{1-\tau}
$$

as $\beta_{\pi} \rightarrow \infty$, 10 and (11) establish that $\varepsilon_{\varphi,(1-\tau)} \rightarrow \beta_{\alpha}$ and $\varepsilon_{\Phi,(1-\tau)} \rightarrow \beta_{\alpha}-1$; as $\beta_{\pi} \rightarrow 1$ with $\theta>0$, (13) and (14) imply that $\varepsilon_{\varphi,(1-\tau)} \rightarrow 0$ and $\varepsilon_{\Phi,(1-\tau)} \rightarrow 0$.

Proof of Proposition 2. (7) implies $\varepsilon_{\varphi, \lambda}=1$ and (8) implies $\varepsilon_{\Phi, \lambda}=1$.

Proof of Proposition 3. (9) implies that $E\left[\nu \cdot r_{i} \mid \alpha_{i}>\bar{\alpha}\right]$ is increasing in $\tau$ and (7) implies that $\varphi$ is declining with $\tau ;(9)$ implies that $E\left[\nu \cdot r_{i} \mid \alpha_{i}>\bar{\alpha}\right]$ does not vary with $\lambda$ and (7) implies that $\varphi$ is declining with $\lambda$. 


\section{References}

Abrams, David, Ufuk Akcigit, and Jillian Popadak (2013). "Patent Value and Citations: Creative Destruction or Strategic Disruption?" Working Paper No. 19647, National Bureau of Economic Research.

Acemoglu, Daron, Ufuk Akcigit, and Murat A. Celik (2014). "Young, Restless and Creative: Openness to Disruption and Creative Innovations." Working Paper No. 19894, National Bureau of Economic Research.

Aghion, Philippe, Ufuk Akcigit, Ari Hyytinen, and Otto Toivanen (2017). "The Social Origins of Inventors." Working Paper No. 24110, National Bureau of Economic Research.

Aghion, Philippe and Peter Howitt (1992). "A Model of Growth Through Creative Destruction." Econometrica, 60(2), 323-351.

Aghion, Philippe and Jean Tirole (1994). "The Management of Innovation." The Quarterly Journal of Economics, 109(4), 1185-1209.

Akcigit, Ufuk, Salome Baslandze, and Stefanie Stantcheva (2016). "Taxation and the International Mobility of Inventors." The American Economic Review, 106(10), 2930-2981.

Akcigit, Ufuk, John Grigsby, and Tom Nicholas (2017a). "The Rise of American Ingenuity: Innovation and Inventors of the Golden Age." Working Paper No. 23047, National Bureau of Economic Research.

Akcigit, Ufuk, John Grigsby, Tom Nicholas, and Stefanie Stantcheva (2018). "Taxation and Innovation in the 20th Century." Working Paper No. 24982, National Bureau of Economic Research.

Akcigit, Ufuk, Douglas Hanley, and Stefanie Stantcheva (2017b). "Optimal Taxation and R\&D Policy." Working Paper No. 22908, National Bureau of Economic Research.

Atkinson, Anthony B., Thomas Piketty, and Emmanuel Saez (2011). "Top Incomes in the Long Run of History." Journal of Economic Literature, 49(1), 3-71.

Becker, Bettina (2015). "Public R\&D Policies and Private R\&D Investment: A Survey of the Empirical Evidence." Journal of Economic Surveys, 29(5), 917-942.

Bell, Alex, Raj Chetty, Xavier Jaravel, Neviana Petkova, and John Van Reenen (2017). "Who Becomes an Inventor in America? The Importance of Exposure to Innovation." Working Paper No. 24062, National Bureau of Economic Research.

Bell, Alex, Raj Chetty, Xavier Jaravel, Neviana Petkova, and John Van Reenen (2019). "Who Becomes an Inventor in America? The Importance of Exposure to Innovation." The Quarterly Journal of Economics. Forthcoming.

Bloom, Nicholas, Mark Schankerman, and John Van Reenen (2013). "Identifying Technology Spillovers and Product Market Rivalry." Econometrica, 81(4), 13471393.

Chen, Zhao, Zhikuo Liu, Juan Carlos Suarez Serrato, and Daniel Yi Xu (2018). "Notching R\&D Investment with Corporate Income Tax Cuts in China." Working Paper No. 24749, National Bureau of Economic Research. 
Dechezlepretre, Antoine, Elias Einio, Ralf Martin, Kieu-Trang Nguyen, and John Van Reenen (2016). "Do tax incentives for research increase firm innovation? An RD design for R\&D." GRI Working Papers 230, Grantham Research Institute on Climate Change and the Environment.

Depalo, Domenico and Sabrina Di Addario (2014). "Shedding Light on Inventors' Returns to Patents." Institute for research on labor and employment, working paper series, Institute of Industrial Relations, UC Berkeley.

Ederer, Florian and Gustavo Manso (2013). "Is Pay-for-Performance Detrimental to Innovation." Management Science, 59(7), 1496-1513.

Freeman, Richard and John Van Reenen (2009). "What If Congress Doubled R\&D Spending on the Physical Sciences?" Innovation Policy and the Economy, 9, 1-38. Giuri, Paola, Myriam Mariani, Stefano Brusoni, Gustavo Crespi, Dominique Francoz, Alfonso Gambardella, Walter Garcia-Fontes, Aldo Geuna, Raul Gonzales, Dietmar Harhoff, Karin Hoisl, Christian Le Bas, Alessandra Luzzi, Laura Magazzini, Lionel Nesta, Önder Nomaler, Neus Palomeras, Pari Patel, Marzia Romanelli, and Bart Verspagen (2007). "Inventors and Invention Processes in Europe: Results from the PatVal-EU Survey." Research Policy, 36(8), 1107-1127.

Goolsbee, Austan (1998). "Does Government R\&D Policy Mainly Benefit Scientists and Engineers?" American Economic Review, 88(2), 298-302.

Griliches, Zvi (1984). R\&D, Patents, and Productivity. University of Chicago Press.

Griliches, Zvi (1990). "Patent Statistics as Economic Indicators: A Survey." Journal of Economic Literature, 28(4), 1661-1707.

Hall, Bronwyn, Adam Jaffe, and Manuel Trajtenberg (2005). "Market Value and Patent Citations." RAND Journal of Economics, pp. 16-38.

Hall, Bronwyn and Nathan Rosenberg (eds.) (2010). Handbook of the Economics of Innovation, vol. 1. 1 ed., Elsevier.

Howell, Sabrina T. (2017). "Financing Innovation: Evidence from R\&D Grants." American Economic Review, 107(4), 1136-64.

Hsieh, Chang-Tai, Erik Hurst, Charles I. Jones, and Peter Klenow (2016). "The Allocation of Talent and U.S Economic Growth." Working Paper No. 18693, National Bureau of Economic Research.

Jaffe, Adam B., Manuel Trajtenberg, and Rebecca Henderson (1993). "Geographic localization of knowledge spillovers as evidenced by patent citations." The Quarterly Journal of Economics, 108(3), 577-598.

Jaimovich, Nir and Sergio Rebelo (2017). "Non-linear Effects of Taxation on Growth." Journal of Political Economy, 125(1), 265-291.

Jones, Benjamin, E. J. Reedy, and Bruce A. Weinberg (2014). "Age and Scientific Genius." Working Paper No. 19866, National Bureau of Economic Research.

Jung, Taehyun and Olof Ejermo (2014). "Demographic Patterns and Trends in Patenting: Gender, Age and Education of Inventors." Technological Forecasting and Social Change, 86, 110-124.

Kline, Patrick, Neviana Petkova, Heidi Williams, and Owen Zidar (2017). "Who Profits from Patents? Rent-sharing at Innovative Firms." Working paper, UCLA Institute for Research on Labor and Employment. 
Kogan, Leonid, Dimitris Papanikolaou, Amit Seru, and Noah Stoffman (2017). "Technological innovation, resource allocation, and growth." The Quarterly Journal of Economics, 132(2), 665-712.

Lerner, Josh and Julie Wulf (2007). "Innovation and Incentives: Evidence from Corporate R\&D." The Review of Economics and Statistics, 89(4), 634-644.

Li, Guan-Cheng, Ronald Lai, Alexander D'Amour, David M. Doolin, Ye Sun, Vetle Torvik, Amy Z. Yu, and Lee Fleming (2014). "Disambiguation and co-authorship networks of the U.S. patent inventor database (1975-2010)." Research Policy, 43(6), 941-955.

Lindquist, Matthew J., Joeri Sol, and Mirjam Van Praag (2015). "Why Do Entrepreneurial Parents Have Entrepreneurial Children?" Journal of Labor Economics, 33(2), 269-296.

Lockwood, Benjamin B., Charles G. Nathanson, and E. Glen Weyl (2017). "Taxation and the Allocation of Talent." Journal of Political Economy, 125(5), 1635-1682.

Manso, Gustavo (2011). "Motivating Innovation." The Journal of Finance, 66(5), 1823-1860.

Moretti, Enrico and Daniel J. Wilson (2017). "The Effect of State Taxes on the Geographical Location of Top Earners: Evidence from Star Scientists." American Economic Review, 107(7), 1858-1903.

Mowery, David C. and Nathan Rosenberg (1991). Technology and the pursuit of economic growth. Cambridge University Press.

Organisation for Economic Co-operation and Development (2009). OECD Patent Statistics Manual 2009. OECD.

Romer, Paul M. (1990). "Endogenous Technological Change." Journal of Political Economy, 98(5, Part 2), S71-S102.

Romer, Paul M. (2000). "Should the Government Subsidize Supply or Demand in the Market for Scientists and Engineers?" Working Paper No. 7723, National Bureau of Economic Research.

Roy, Andrew D. (1951). "Some Thoughts on the Distribution of Earnings." Oxford Economic Papers, 3(2), 135-146.

Scherer, Frederic M., Dietmar Harhoff, and Joerg Kukies (2000). "Uncertainty and the Size Distribution of Rewards from Innovation." Journal of Evolutionary Economics, $10(1), 175-200$.

Schmookler, Jacob (1957). "Inventors Past and Present." The Review of Economics and Statistics, 39(3), 321-333.

Toivanen, Otto and Lotta Vaananen (2012). "Returns to Inventors." The Review of Economics and Statistics, 94(4), 1173-1190.

Wilson, Daniel (2009). "Beggar thy Neighbor? The In-State, Out-of-State, and Aggregate Effects of R\&D Tax Credits." The Review of Economics and Statistics, $91,431-436$. 
TABLE 1

Summary Statistics for Inventors Analysis Sample

\begin{tabular}{|c|c|c|c|}
\hline & Mean & $\underline{\text { Median }}$ & $\underline{\text { Std. Dev. }}$ \\
\hline Patent Grants & 3.0 & 1.0 & 6.5 \\
\hline Patent Applications & 3.2 & 1.0 & 11.1 \\
\hline Patent Citations & 26.2 & 1.0 & 118.1 \\
\hline Number of Collaborators & 4.7 & 2.0 & 8.2 \\
\hline Age at Application & 43.7 & 43 & 11.5 \\
\hline Individual Wage Earnings (\$) & 111,457 & 83,000 & 140,463 \\
\hline Total Individual Income (\$) & 188,782 & 100,000 & 567,813 \\
\hline
\end{tabular}

Female Share

0.131

Number of Individuals in Sample

Notes: This table presents summary statistics for the 1,200,689 inventors used in the empirical analysis. We define individuals as inventors if they were listed as an inventor on a patent application between 2001-2012 or grant between 1996-2014 and linked to the tax data. Citations are measured as total patent citations between 19962014. The number of collaborators is measured as the number of distinct individuals that the inventor has ever co-authored a patent grant or application with in our linked dataset. For individuals with more than one patent application, age at application is the age at a randomly selected patent application filing. Incomes are measured in 2012. Individual wage earnings is defined as total earnings reported on an individual's W-2 forms. Total individual income is defined for tax filers as Adjusted Gross Income (as reported on the 1040 tax return) minus the spouse's W-2 wage earnings (for married filers). For non-filers, total individual income is defined as wage earnings. In this table only, wage earnings are top-coded at $\$ 1$ million and total individual income is top-coded at $\$ 10$ million. Median income variables are rounded to the nearest thousand dollars. See Section 2A and Bell et al. (2019) for further details on sample and variable definitions. 
A. Inventors' Income Distribution, Ages 40-50

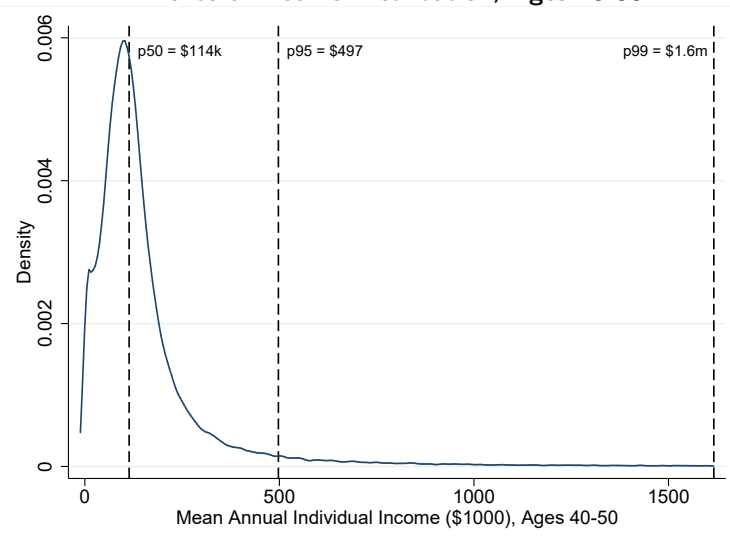

B. Inventors' Incomes vs. Patent Citations

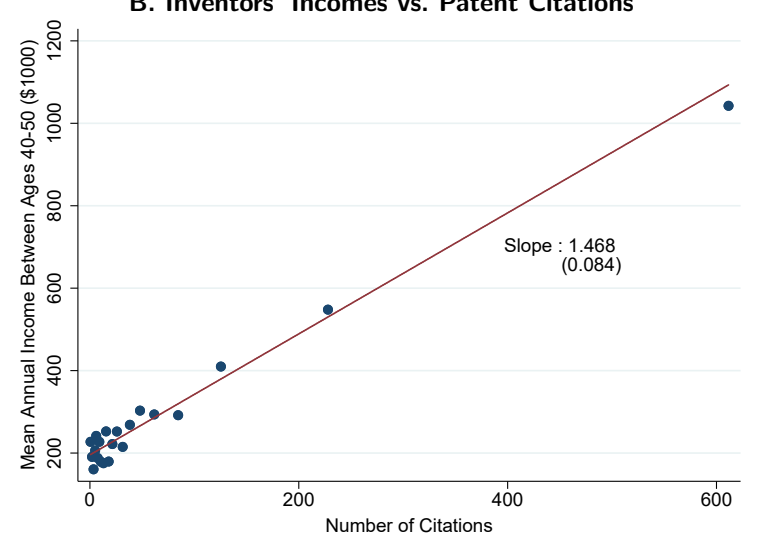

Figure 1. Cross-Sectional Income Distribution of Inventors. This figure is reproduced from Online Appendix Figure V of Bell et al. (2019). In both panels, the sample consists of all individuals in our full inventors sample born between the ages of 1959-1962, for whom we see income at all ages between 40 and 50. Income is measured at the individual level and includes both labor and capital income; see Section II for details. Panel A plots a kernel density of the distribution of inventors' income, measured as mean annual income over ages 40-50 in 2012 dollars. For scaling purposes, the top and bottom percentiles of the distribution are omitted when plotting this density. Panel B presents a binned scatter plot of average annual income between ages 40 and 50 vs. the total number of citations an inventor obtains. For this panel, we further limit the sample to the 13,875 individuals who applied for a patent in 1996 to maximize the time horizon over which we can measure future citations. This plot is constructed by dividing citations into 21 bins and plotting mean income vs. mean citations within each bin. The first 19 bins include inventors in the first 19 ventiles $(5 \%$ bins) of the citations distribution, while the last two bins plot the same relation for the 95th to 98th percentiles and the 99th percentile of the citation distribution. The best fit line and slope shown on the figure are estimated using an OLS regression on the 21 points, weighted by the number of inventors in each bin. The standard error of the slope estimate is reported in parentheses. 
A. Age Distribution of Individuals who Patent in 2000

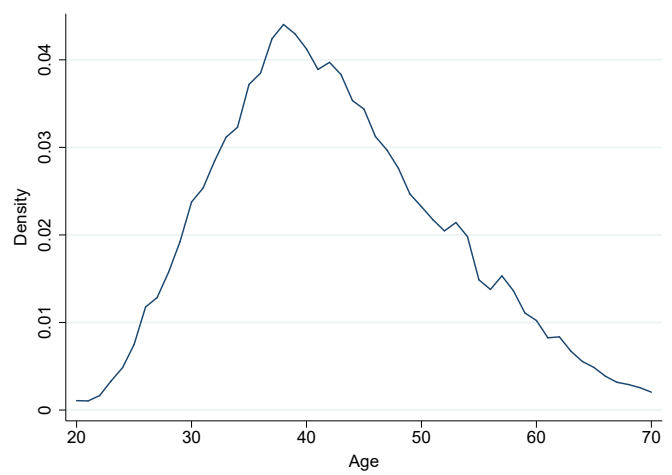

B. Fraction of Workers who Patent in 2000, by Age

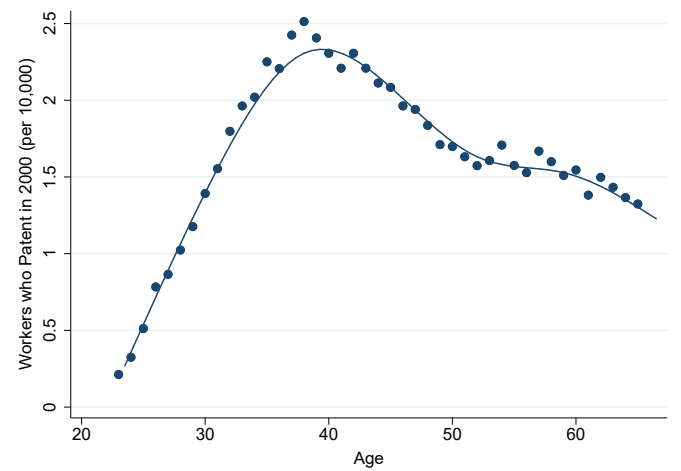

C. Fraction of Workers with Highly-Cited Patents, by Age

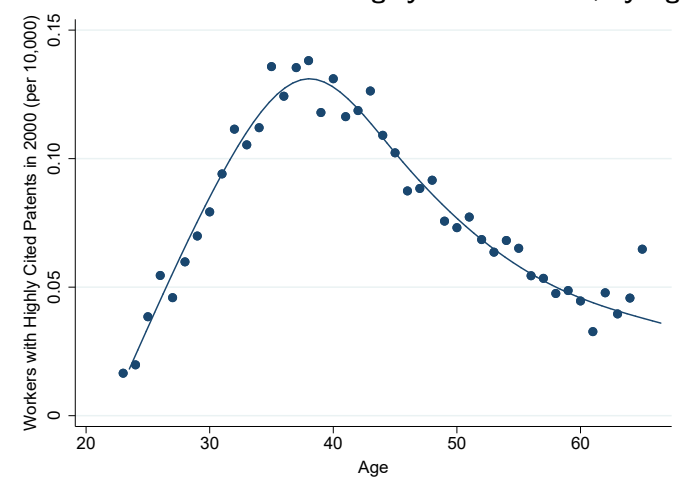

Figure 2. Age Profile of Innovation. This figure examines the age distribution of inventors. The sample consists of individuals in our full inventors sample who applied for a patent in 2000 that was subsequently granted. Panel A presents a kernel density of the age distribution of these inventors. Panel B plots the fraction of workers (individuals with positive W-2 earnings) who patent in 2000 by age. Panel C plots the fraction of workers who filed a patent application in 2000 that went on to become highly-cited (in the top 5\% of the distribution). The curves in Panels B and C are cubic splines. 


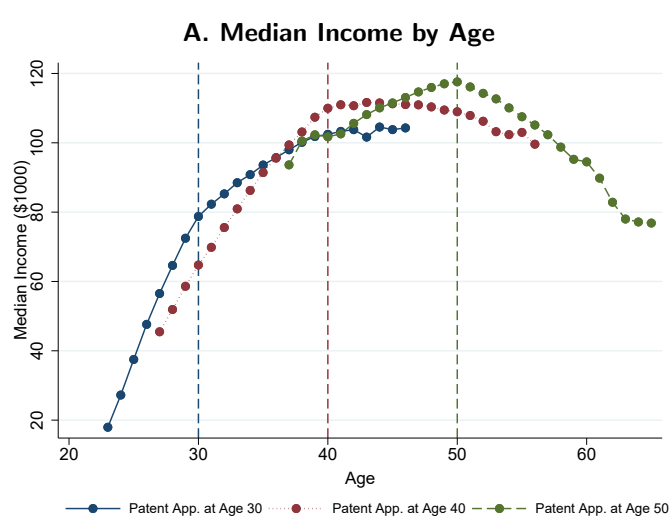

\section{B. Event Study of Income Distributions Around Patent Application}

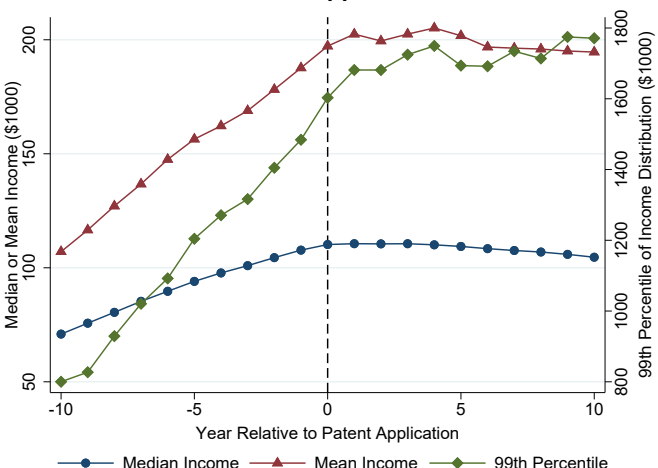

C. Event Study of Median Income around Patent Application, by Patent Quality

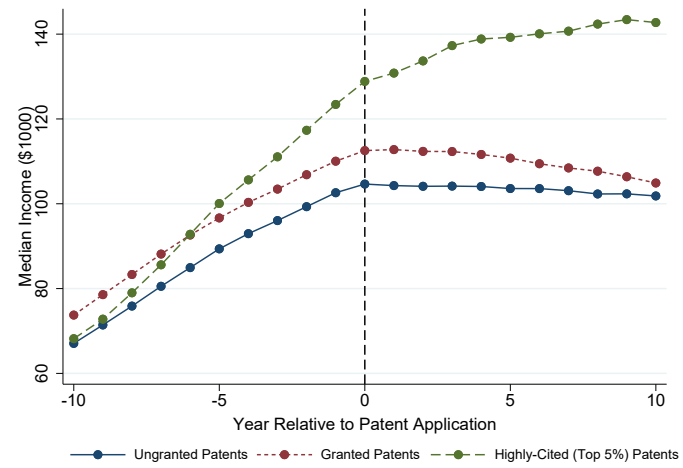

Figure 3. Income Profiles of Inventors. This figure plots the income profiles of inventors before and after they file patent applications using all individuals for whom the relevant data is available in our full inventors sample. Income is measured as total income (including wage earnings and capital income) at the individual level; see Section II for details. Panel A plots the median incomes by age of inventors who file a patent application at either age 30, 40, or 50 over the range of ages for which their incomes are observed (between 1996-2012). Panel B generalizes this analysis using an event study framework, defining year 0 as the year in which an individual files a patent application and other years relative to this reference year (e.g., +1 is the year after the application). In this panel, we limit the sample to individuals who file patent applications between ages 35 and 50. For individuals who file multiple patents in this age window, we choose one of the patents at random to define the reference year. We plot the mean and median (left y axis) and 99th percentile (right y axis) of the income distribution of inventors in each year relative to the event year. Panel C replicates the median income series in Panel B, separating inventors into three groups: those whose patent applications were not granted; those whose applications were granted; and those with patents granted that went on to have citations in the top $5 \%$ of the distribution relative to other patents granted in the same year. 


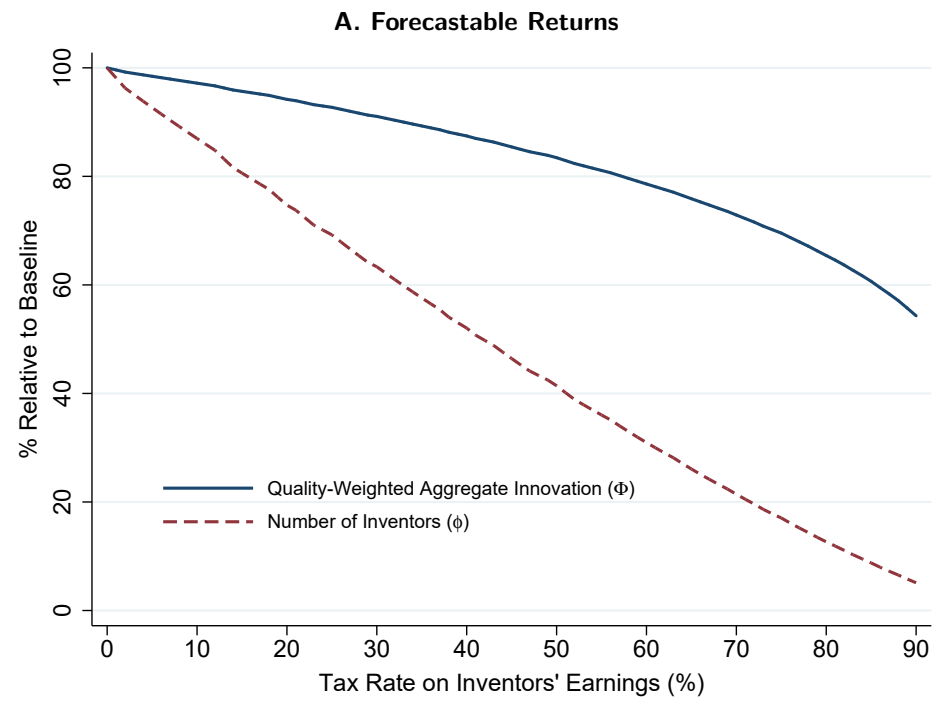

B. Stochastic Returns

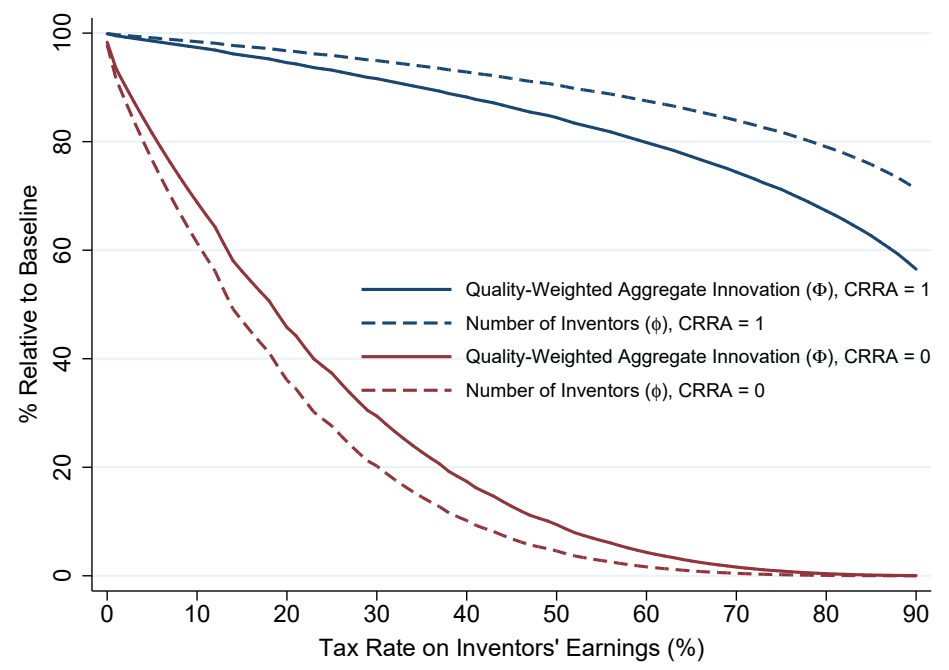

Figure 4. Predicted Impacts of Tax Rates on Innovation. This figure plots the fraction of inventors $(\varphi)$ and aggregate quality-weighted innovation $(\Phi)$ vs. the tax rate on inventors' earnings predicted by our model of career choice. Panel A considers the case where the variation in private financial returns to innovation is driven purely by differences in ability across inventors and hence is perfectly forecastable at the time of career choice. Panel B considers the case where the variance in private returns come primarily from stochastic shocks, with a coefficient of relative risk aversion $\theta=0$ (linear utility) or 1 (log utility). The shape parameters for the Pareto distributions of stochastic returns and innovation abilities, denoted $\beta_{\pi}$ and $\beta_{\alpha}$ in the model, are chosen such that the inventors' earnings distribution generated by the model matches the Pareto shape parameter of 1.26 estimated using inventors' empirical earnings distribution in Figure 1, i.e. such that $\left(\beta_{\pi} /\left(\beta_{\pi}-1\right)\right) \cdot\left(\beta_{\alpha} /\left(\beta_{\alpha}-1\right)\right)=1.26 /(1.26-1)$. In Panel $\mathrm{B}$, stochastic returns account for $90 \%$ of total skewness in inventors' earnings, i.e. $s \equiv\left(\left(\beta_{\pi} /\left(\beta_{\pi}-1\right)\right)-1\right) /\left(\beta_{\alpha} /\left(\beta_{\alpha}-1\right)-1+\left(\beta_{\pi} /\left(\beta_{\pi}-1\right)-1\right)=0.9\right.$. In each series, the level of innovation is normalized to $100 \%$ when the tax rate is 0 . The normalized values are invariant to the other parameters of the model $\left(w_{\bar{I}}, \lambda\right.$, and $\theta$ in Panel A). 